\title{
POPULATION DYNAMICS OF THE MACKENZIE DELTA REINDEER HERD, 1938-1958
}

\author{
Charles J. Krebs*
}

$\mathbf{T}$ HE value of the reindeer (Rangifer tarandus) as a domestic grazing animal of the arctic and subarctic regions has long been known in Eurasia. In 1926 Canada considered establishing reindeer in the arctic and commissioned A. E. Porsild to undertake a 2.5-year survey of the country between the Alaska-Yukon boundary on the west, the Coppermine River on the east, Great Bear Lake on the south, and the Arctic Ocean on the north, to determine the best area to locate a reindeer herd. As a result of this survey (Porsild 1929) a 6600-square-mile Reindeer Grazing Preserve was set up just northeast of the Mackenzie Delta, N.W.T.

The reindeer to be used for the introduction were purchased in Alaska in 1929. They were driven 1600 miles from Kotzebue Sound on the west coast of Alaska to the east bank of the Mackenzie River. The trip was begun with 3440 reindeer in December 1929, and the herd had dwindled to 2370 animals when it reached the Mackenzie River in March 1935 (Crerar and Bonnycastle 1936).

The original plan of the experiment was to set up a main herd of reindeer owned by the government that would form a nucleus. Periodically from this nucleus smaller herds would be cut out. These smaller herds, the native herds, would be turned over to suitable Eskimos and each herd would be given its own winter and summer ranges. Ultimately it was hoped that these native herds would become self-supporting units, managed by Eskimos. Unfortunately this objective has never been completely realized. Since 1936 six separate native herds have been established and all but one have been failures (one herd established in 1954 was still in operation in 1959).

A considerable body of data, none of which had been analyzed, on the population changes of these herds was extracted from the files of the Reindeer Station, Aklavik, N.W.T. by the writer. Part of this information was obtained at annual roundups of each of the herds commencing in 1936. During the roundup a record of the number of animals in each sex and age class was obtained. Some of the figures given include estimates (see below) of groups of animals that either could not be corralled or subsequently escaped. All other figures refer to actual counts. Additional data were extracted from monthly tallies of the known reductions (slaughter, predation, etc.) in each herd.

*Department of Zoology, University of British Columbia, Vancouver. 
The purpose of this paper is first to analyze the changes undergone by the reindeer population during the period 1938-1958 in terms of birth rate, death rate, and dispersal rate, and second to investigate the effect of herd size and composition on birth rate and dispersal rate.

\section{Changes in total numbers}

An over-all picture of the fluctuations in the Mackenzie Delta reindeer herd is shown in Figure 1, which gives the changes in total numbers of all herds combined over the period 1938-1958. Error limits, represented by vertical lines, have been placed on those totals in which any estimation was involved. These error limits have been selected arbitrarily as +20 per cent and -50 per cent of the estimates, since estimates of this type tend to be high rather than low (Pulk 1958), and it is believed that this range should include the true number estimated. For example, if 1000 animals were estimated to have escaped corralling, the error limits on this estimate would be placed at $1000-500$ and $1000+200$, or between 500 and 1200 animals.

The components on which this curve is based, that is, the main herd and the several native herds, could now be analyzed, but this does not seem necessary here. In summary, six native herds were cut out from the main herd between 1939 and 1954. Usually about 1200 to 1800 reindeer were used to start a native herd. Almost all native herds showed the same pattern of change, i.e., rising numbers for a few years and then a steady decline resulting in the liquidation of the herd when the remaining reindeer were returned to the main herd. Detailed information on all native herds may be found in Krebs (1959).

\section{Causes of changes in numbers}

There are three forces that govern the rise and fall of all animal population - birth rate, death rate, and dispersal rate (immigration and emigration). Any fluctuation in total numbers can be ascribed to changes in one or more of these forces, and thus an assessment of these three factors is needed to analyze the population dynamics of any group of animals.

An assessment of these three factors for the Mackenzie Delta reindeer may be made in the following way. Birth rate may be measured by the annual number of fawns provided by actual counts made in late July each year at the roundup. This is of course not the true birth rate, since fawning occurs during April and May, but the fawn losses are almost always slight, approximately 2 to 15 per cent of the total fawns in this herd, in contrast to not infrequent heavy calf losses in the Canadian caribou (Kelsall 1957). Death rate is derived from the known reductions through slaughter, sickness, injury, predators, drowning, and other causes that are recorded each month by the chief herder. Slaughter is by far the most important cause of 
death. Dispersal rate may be measured by the number of animals "unaccounted for." Each roundup count usually reveals a discrepancy between theoretical and actual herd size, which is tallied as the "number unaccounted for." By far the greater part of this figure is the result of losses from animals straying and hence this figure provides a measure of dispersal rate. The fate of these strays is usually death, although some do join caribou herds to the southeast. It should be realized that the "number unaccounted for" is not strictly an independent variable because it is obtained by subtraction and includes all errors made in assessing the other two variables. Nevertheless, it does not seem that this is a serious objection to the analysis because the two variables "number of fawns" and "number of reductions" are quite accurately determined by actual counts and the error involved in obtaining the "number unaccounted for" must be quite small. It should be clearly realized that in the following discussion both death rate and dispersal rate are factors acting to reduce herd size. The distinction between them regards the kind of reduction, death rate measuring principally the number slaughtered for food and dispersal rate the number lost by straying.

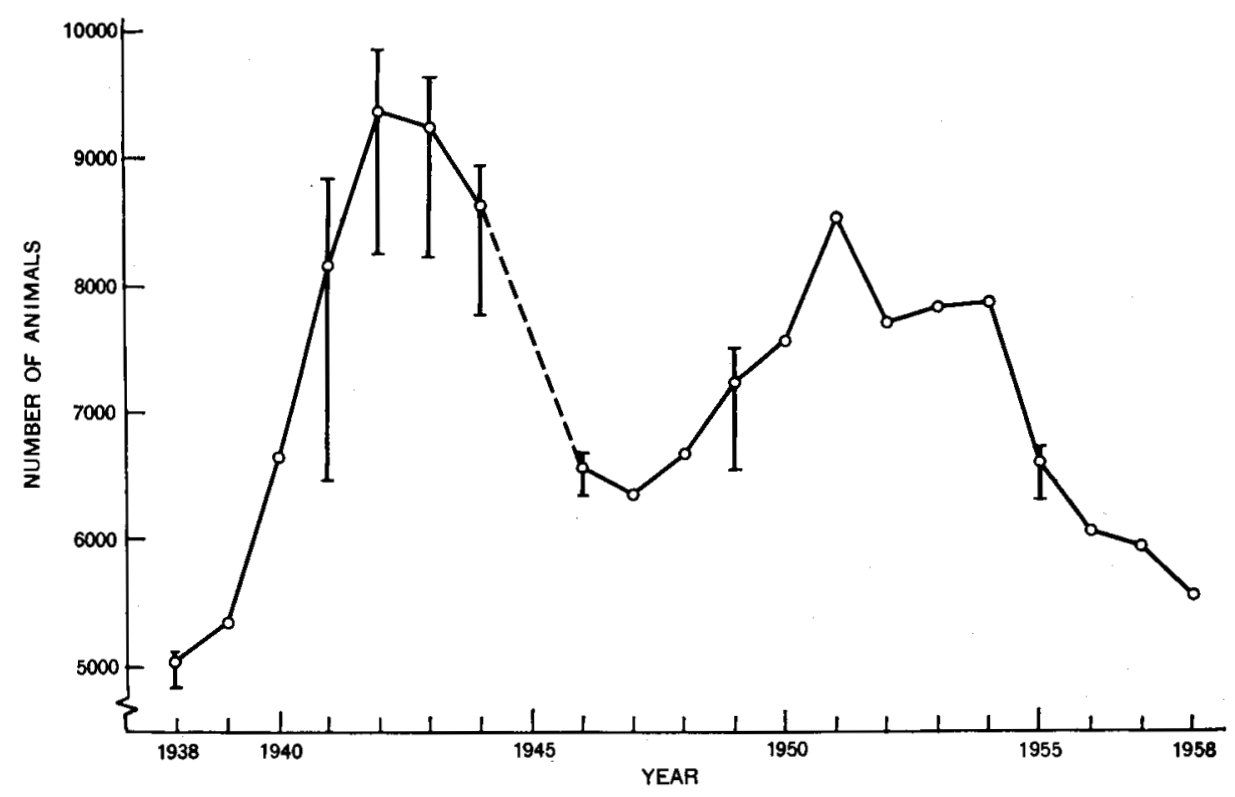

Fig. 1. Total animals in all herds combined, Mackenzie Delta reindeer, 1938-1958. Vertical lines represent error limits of +20 per cent to -50 per cent on those totals in which any estimation was involved. The roundup in 1945 was unsuccessful.

The effect of these three primary factors of population fluctuations on the total annual increment of the herd may be analyzed by means of the techniques of multiple regression and correlation. An explanation of these techniques may be found in Snedecor (1956, Chapter 14) and Walker and Lev (1953, Chapter 13). There are two approaches we could use toward this 
problem: (1) analyze the three factors together, neglecting the fact that dispersal rate is not independently determined; or (2) analyze birth rate and death rate only, omitting the dispersal rate from the analysis. Statistically, however, both these approaches lead to the same numerical result, the dispersal rate of (1) being the equivalent of the error term (Snedecor 1956) of (2). The first approach will be used in the following analysis.

Table 1 lists the figures for total annual increment, birth rate, death rate, and dispersal rate and forms the foundation on which the following analysis is based. Here again we are dealing with the over-all picture, the data for all herds combined.

The question we are attempting to answer using multiple regression analysis is this: which of the three factors of birth rate, death rate, and dispersal rate is most influential in determining the variations in the total annual increment to the herd? Because we are not interested in prediction and the geometrical form of the multiple regression equation, but rather in comparison of the relative importance of three factors, the multiple regression equation is more useful in its standard form. Using the Doolittle Method (Walker and Lev 1953) of solving the normal equations, we obtain for the generalized equation:

$$
\mathrm{Y}^{*}=\mathrm{b}^{*}{ }_{\mathrm{y} 1.23} \mathrm{X}_{1}+\mathrm{b}_{\mathrm{y} 2.13} \mathrm{X}_{2}+\mathrm{b}_{\mathrm{y} 3.12}^{*} \mathrm{X}_{3}
$$

and the following for the reindeer data:

$$
\mathrm{Y}^{*}=0.342 \mathrm{X}_{1}+(-0.475) \mathrm{X}_{2}+(-0.674) \mathrm{X}_{3}
$$

where $\mathrm{Y}^{*}=$ estimated standard measure value of total annual increment

$\mathrm{X}_{1}=$ birth rate term

$\mathrm{b}^{*}{ }_{\mathrm{y} 1.23}=$ standard partial regression coefficient of $\mathrm{X}_{1}$ on $\mathrm{Y}$

$\mathrm{X}_{2}=$ death rate term

$\mathrm{b}^{*}{ }_{\mathrm{y} 2.13}=$ standard partial regression coefficient of $\mathrm{X}_{2}$ on $\mathrm{Y}$

$\mathrm{X}_{3}=$ dispersal rate term

$\mathrm{b}^{*}{ }_{\mathrm{y3.12}}=$ standard partial regression coefficient of $\mathrm{X}_{3}$ on $\mathrm{Y}$

The negative values of $b^{*}{ }_{y 2.13}$ and $b^{*}{ }_{\mathrm{y} 3.12}$ imply that as $\mathrm{X}_{2}$ or $\mathrm{X}_{3}$ increases, $\mathrm{Y}$ decreases. Since the standard partial regression coefficients are in standard measure and hence independent of the scale or variability of the variables, they can be compared directly. Since $b^{*}{ }_{y 3.12}$ is largest in absolute value, $\mathbf{X}_{3}$, the dispersal rate, is the most important of these three factors in determining the variations in the value of $\mathrm{Y}$, the total annual increment. $\mathrm{X}_{2}$, the death rate, is of less importance, and $\mathrm{X}_{1}$, the birth rate, is of least importance in determining the variations in the value of $Y$ (because $b^{*}{ }_{y 2.13}>b^{*}{ }_{1.23}$ ).

The multiple correlation coefficient may be computed for the above regression to test the significance of the whole regression. This gives a perfect correlation,

$$
R_{y .123}=1.000
$$

Indeed, this is just what would be expected, since by definition

Total Increment $=$ No. born - No. died - No. dispersed

A more precise analysis of the relative importance of the three variables, $\mathrm{X}_{1}, \mathrm{X}_{2}$, and $\mathrm{X}_{3}$, may be made using a breakdown of the sums 
of squares as given by Snedecor (1956, p. 437). These results are given in Table 2. For each of the three variables we obtain the sum of squares that is due to that particular variable after the effects of the other two variables have been removed, thus determining the amount of the total variation that may be attributed to that particular variable alone. Table 2 shows that $X_{3}$, the dispersal rate, accounts for nearly twice as much of the variation observed in $Y$ as does $X_{2}$, the death rate, and for nearly five times as much of the variation observed in $Y$ as does $X_{1}$, the birth rate.

Table 1. Total number, total annual increment, number of fawns, number of reductions, and number unaccounted for, Mackenzie Delta reindeer, all herds combined, 1938-1958.

\begin{tabular}{|c|c|c|c|c|c|}
\hline Year & $\begin{array}{c}\text { Total } \\
\text { number }\end{array}$ & $\begin{array}{c}\text { Total } \\
\text { annual } \\
\text { increment }\end{array}$ & $\begin{array}{c}\text { Number } \\
\text { of } \\
\text { fawns }\end{array}$ & $\begin{array}{c}\text { Number } \\
\text { of } \\
\text { reductions }\end{array}$ & $\begin{array}{l}\text { Number } \\
\text { unaccounted } \\
\quad \text { for }\end{array}$ \\
\hline 1938 & 5031 & - & - & - & - \\
\hline 1939 & 5342 & 311 & 1896 & 997 & 588 \\
\hline 1940 & 6635 & 1293 & 1934 & 422 & 219 \\
\hline 1941 & 8157 & 1522 & 2141 & 549 & 70 \\
\hline 1942 & 9374 & 1217 & 2411 & 865 & 329 \\
\hline 1943 & 9231 & -143 & 2287 & 1250 & 1180 \\
\hline 1944 & 8609 & -622 & 2173 & 1571 & 1224 \\
\hline 1945 & - & - & - & - & \\
\hline 1946 & 6568 & -1000 & 2189 & 964 & 2225 \\
\hline 1947 & 6343 & -225 & 1780 & 734 & 1271 \\
\hline 1948 & 6679 & 336 & 1857 & 813 & 708 \\
\hline 1949 & 7219 & 540 & 2104 & 784 & 780 \\
\hline 1950 & 7560 & 341 & 2133 & 681 & 1111 \\
\hline 1951 & 8522 & 962 & 2302 & 790 & 550 \\
\hline 1952 & 7697 & -825 & 2206 & 1268 & 1763 \\
\hline 1953 & 7814 & 117 & 2243 & 1390 & 736 \\
\hline 1954 & 7844 & & 2172 & 1427 & 715 \\
\hline 1955 & 6595 & -1249 & 1743 & 1786 & 1206 \\
\hline 1956 & 6075 & -520 & 1535 & 1183 & 872 \\
\hline 1957 & 5941 & -134 & 1712 & 1288 & 558 \\
\hline 1958 & 5571 & -370 & 1521 & 652 & 1239 \\
\hline
\end{tabular}

Table 2. Breakdown of the multiple regression sum of squares into its components.

\begin{tabular}{|c|c|c|c|c|}
\hline Source of variation & Sum of squares & $d . f$. & Per cent of total & Ratio \\
\hline $\mathrm{X}_{1} \underset{\text { after }}{\mathrm{X}_{2}}+\mathrm{X}_{3}$ & $1,280,554$ & 1 & 11.6 & 0.2 \\
\hline$\underset{\text { (mortality) }}{X_{2} \text { after } X_{1}+X_{3}}$ & $3,560,302$ & 1 & 32.3 & 0.6 \\
\hline $\mathrm{X}_{3} \underset{\text { (disner }}{\operatorname{after}} \mathrm{X}_{1}+\mathrm{X}_{2}$ & $6,184,088$ & 1 & 56.1 & 1.0 \\
\hline Error & 0 & 16 & 0 & \\
\hline Total & $11,024,944$ & 19 & 100.0 & \\
\hline
\end{tabular}

Thus fluctuations in the total annual increment of the Mackenzie Delta reindeer herd over the period 1938-1958 were due primarily to the dispersal rate, secondarily to the death rate, and least of all to the birth rate. It 
does not seem feasible to extend this type of analysis to an individual herd basis because the number of observations (years) is too small to permit a meaningful statistical analysis.

Losses by straying have been recognized by the government as an important drain on the reindeer herds. Since 1938 straying losses have totalled about 17,000 animals. Steps are now being taken to decrease straying losses by fencing part of the range.

\section{Age distribution}

The age distribution of a population is important from the point of view of both reproduction and mortality. Mortality usually varies with age and reproduction is restricted to certain age groups. The proportion of the reproducing fraction of the population determines in part the reproductive rate. An expanding population characteristically shows a prevalence of the young age groups.

Because of its domestic nature the reindeer presents a rather artificial age distribution. Because there is an annual selective slaughter of animals, the age distribution is directly affected by man and does not represent a situation that would be found in nature. The tendency at the annual slaughter is to select the older mature animals and the 5- to 7-year-old steers. Because of this the possibility exists of setting up an optimum age distribution that will afford a maximum rate of reproduction in conformity with the desired herd size, slaughter yield, and composition. In practice this optimum age distribution cannot be achieved because of practical difficulties, but it is at least approached.

Table 3. Age distribution, Mackenzie Delta reindeer, all herds combined, 1938-1958.

\begin{tabular}{|c|c|c|c|c|c|c|c|c|c|}
\hline \multirow{2}{*}{ Year } & \multicolumn{2}{|c|}{ Females } & \multicolumn{2}{|c|}{ Bulls } & \multicolumn{2}{|c|}{ Steers } & \multicolumn{3}{|c|}{ Fawns } \\
\hline & adult & yearling & adult & yearling & adult & yearling & female & male & castrated \\
\hline 1938 & 1839 & 469 & 329 & 530 & 447 & - & 719 & 698 & $\longrightarrow$ \\
\hline 1939 & 1859 & 672 & 387 & 514 & 303 & 57 & 772 & 758 & 20 \\
\hline 1940 & 2161 & 820 & 389 & 375 & 547 & 409 & 918 & 370 & 646 \\
\hline 1941 & 2610 & 936 & 548 & 467 & 907 & 548 & 1119 & 720 & 302 \\
\hline 1942 & 3356 & 1036 & 439 & 629 & 999 & 504 & 1206 & 809 & 396 \\
\hline 1943 & 3690 & 1140 & 511 & 632 & 867 & 104 & 1141 & 614 & 532 \\
\hline 1944 & 3081 & 1073 & 621 & 552 & 1081 & 28 & 1050 & 815 & 308 \\
\hline 1945 & - & - & - & - & - & - & - & - & - \\
\hline 1946 & 2580 & 774 & 81 & 211 & 601 & 132 & 1131 & 404 & 654 \\
\hline 1947 & 2387 & 795 & 105 & 217 & 507 & 552 & 870 & 437 & 473 \\
\hline 1948 & 2205 & 1187 & 185 & 220 & 353 & 672 & 942 & 415 & 500 \\
\hline 1949 & 2821 & 683 & 195 & 242 & 656 & 518 & 1037 & 589 & 478 \\
\hline 1950 & 2841 & 739 & 316 & 345 & 717 & 469 & 1086 & 695 & 352 \\
\hline 1951 & 3285 & 821 & 300 & 477 & 910 & 427 & 1141 & 555 & 606 \\
\hline 1952 & 3167 & 503 & 317 & 150 & 996 & 358 & 1059 & 631 & 516 \\
\hline 1953 & 2862 & 807 & 246 & 422 & 844 & 388 & 1113 & 607 & 525 \\
\hline 1954 & 3053 & 716 & 320 & 338 & 733 & 512 & 1044 & 517 & 611 \\
\hline 1955 & 2566 & 593 & 325 & 218 & 686 & 464 & 837 & 523 & 383 \\
\hline 1956 & 2554 & 539 & 339 & 282 & 499 & 327 & 794 & 241 & 500 \\
\hline 1957 & 2516 & 370 & 286 & 126 & 601 & 330 & 841 & 871 & - \\
\hline 1958 & 2204 & 476 & 289 & 584 & 497 & $\ldots$ & 738 & 783 & - \\
\hline
\end{tabular}


Table 3 presents the age distribution of the Mackenzie Delta reindeer, all herds combined, for 1938 to 1958 . The data for 1938 to 1947 and 1949 to 1950 include groups of animals whose numbers were estimated but which were not segregated into sex and age classes (usually less than 5 to 10 per cent of the total). These animals were distributed in all the sex and age classes in the same proportions as found in the segregated and classified groups. The data for the other years are actual counts. Some discrepancy will be noted from one year to the next in certain groups (e.g. fawns castrated in relation to yearling steers). These discrepancies are the result of two things: (1) inaccurate classification of animals by workers at the roundup; and (2) the apportionment procedure for incorporating unclassified groups into the totals.

Table 4 summarizes the percentage age composition of the herd over the period 1938 to 1958 by giving the average and range for each age class in the population.

The question may be asked, what is the relationship between the sex and age distribution and the observed changes in abundance and productivity of the herd? Any changes caused by sex and age distribution must show their effects on the birth rate, the death rate, or the dispersal rate. Of these three we may dismiss the effects on the death rate because the death rate is artificially determined, being selective both to age and sex.

Table 4. Percentage age composition of the Mackenzie Delta reindeer herd over the period 1938-1958.

\begin{tabular}{lrr}
\hline \multirow{2}{*}{ Age group } & \multicolumn{2}{c}{ Percentage of total herd } \\
\cline { 2 - 3 } & average & \multicolumn{1}{c}{ range } \\
\hline Adult Females & 37.6 & $32.0-42.3$ \\
Yearling Females & 10.6 & $6.2-17.8$ \\
Adult Males & 14.0 & $8.1-19.8$ \\
Yearling Males & 10.1 & $5.2-13.4$ \\
Female Fawns & 13.8 & $12.2-17.2$ \\
Male Fawns & 14.0 & $12.2-16.1$ \\
\hline
\end{tabular}

\section{Effect on birth rate}

Three factors that may directly affect the birth rate have been investigated: (1) number of adult females; (2) herd size; and (3) number of adult bulls. Because of the type of analysis involved it is necessary to restrict discussion to one herd, and hence the following analysis refers to the main herd only.

It would be expected that the number of adult females would affect the birth rate. The regression of the number of adult females against the number of fawns for the main herd only is shown in Figure 2. Although the points are moderately scattered, the correlation coefficient $(r=0.91)$ is highly significant $(P<0.0005)$. This regression indicates that over the interval covered by the data (number of adult females in the main herd 
500-2400) the tendency is for the increase in number of fawns to be about 70 per cent of the increase in the number of adult females, i.e., the addition of 100 more adult females to the herd would result on the average in the production of $\mathbf{7 0}$ more fawns per year. This suggests that fawn production per adult female occured at a relatively constant rate over the interval.

Herd size may affect the birth rate by way of its direct effect on the number of adult females and indirectly by the "herd effect", i.e. by the reproductive rate per adult female being a function of density or herd size. The difficulty encountered here is the separation of these two effects. This may be achieved by computing two regressions: (1) herd size against reproductive rate measured by fawns/adult females expressed as a percentage (main herd only); and (2) herd size against the number of fawns produced (main herd only). The first regression measures only the "herd effect". This was calculated and gave a complete scatter of points $(r=0.0)$, which suggests that no "herd effect" was in operation over the herd size range represented. The second regression in this case measures only the direct effect of increasing the number of adult females. This regression was calculated and, as would be expected, was very similar to Figure 2 and highly significant $(r=0.95, P<0.0005)$.

The number of adult bulls may affect the birth rate if it has any effect on the fertility rate of the cows. Many males are castrated each year to avoid difficulties in herd handling during the rut. It is believed that only about one male in seven is needed for adequate fertilization of the cows. A regression of number of adult bulls against number of fawns was calculated and showed a wide scatter of points with a weak positive correlation ( $\mathrm{r}=0.21, P<0.25$ ). Thus it was concluded that the number of adult bulls showed very little relationship to the number of fawns produced within the limits of these data.

\section{Effect on dispersal rate}

Two factors that might affect dispersal rate are herd size and number of yearlings.

Numerous authors have found in other animals that dispersal rate increases as the population size increases (Errington 1954; Chitty 1955; Kluijver 1951; Andrewartha and Birch 1954, Chapter 5). This effect may be minimized up to a point by the herd instinct of reindeer. The regression of herd size against the "number unaccounted for" was calculated for the main herd and gave a complete scatter of points without correlation $(\mathrm{r}=0.0)$. Thus over the range of herd size of the main herd (1500-6200) during the period 1938 to 1958 there is no apparent relation between herd size and number of straying losses. Nor does there appear to be any relation between herd size and the percentage loss by straying, the points again falling in a complete scatter.

It is believed that most of the strays are yearling animals because this group as a whole tends to wander more than any other (Pulk 1958). 
In view of this, the regression of the number of yearlings against the "number unaccounted for" was calculated for the main herd over the period 1938 to 1958 . This resulted in a complete horizontal scatter of points and a very low non-significant negative correlation $(r=-0.10)$. This suggests that there is no relation between the number of yearlings in the herd and the number of straying losses.

In view of these facts and other information, it seems probable that the number of straying losses is determined principally by factors extrinsic to the herd itself, notably perhaps by weather, insects, and humans as well as by their many interactions.

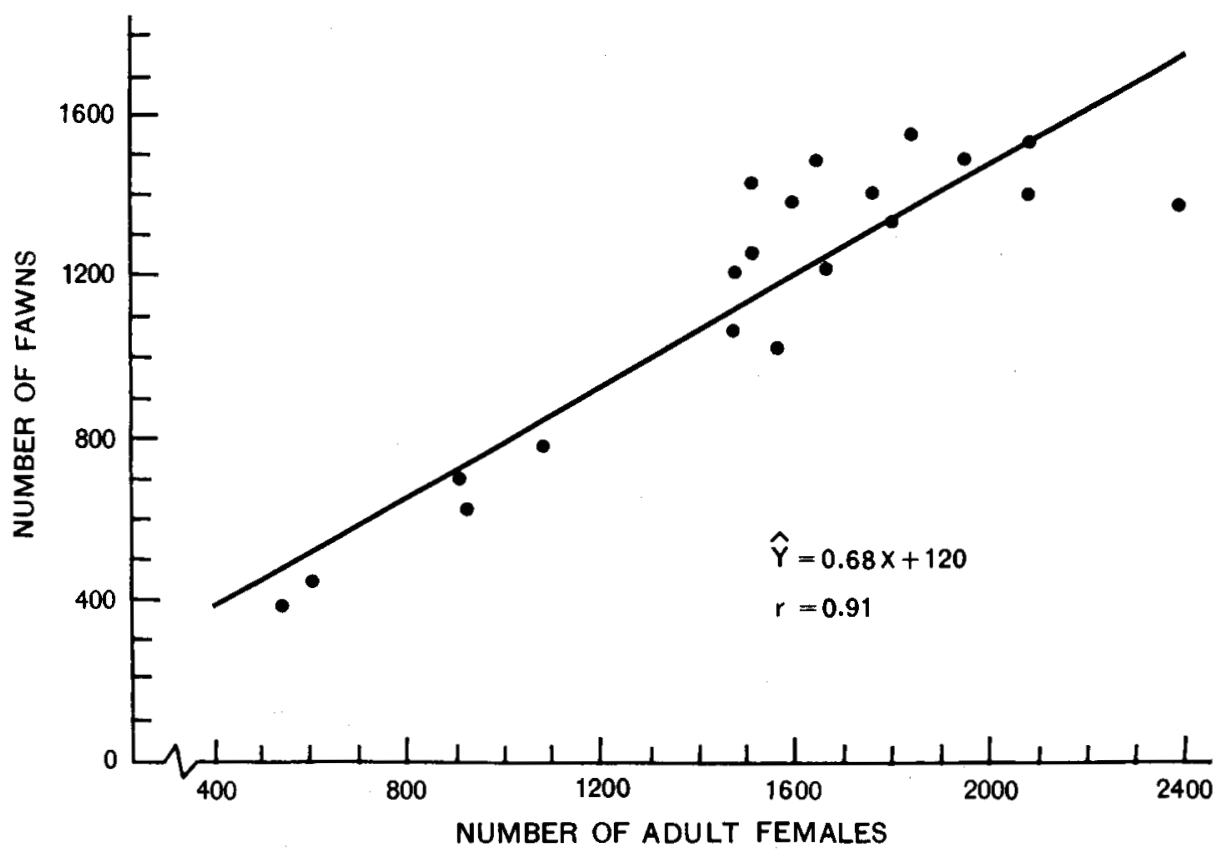

Fig. 2. Relation between the number of adult females and the number of fawns, main herd only, 1938-1958

\section{Summary}

1. A brief history of the Mackenzie Delta reindeer herd is given. This herd has consisted of a nucleus main herd and native herds operated by Eskimo owners. All native herds but one have been liquidated. They show a recurrent pattern of rising numbers for a few years and then decline, usually resulting in liquidation of the herd.

2. The effect of each of the three population determining factors (birth rate, death rate, and dispersal rate) on the total annual increment to the herd is analyzed. It is shown that dispersal rate (losses by straying) was the most important factor and birth rate the least important factor in determining variations in the total annual increment to the herd over the 
period 1938 to 1958 . The relative importance of each is indicated in the following ratio: birth rate, 0.2 ; death rate, 0.6 ; dispersal rate, 1.0.

3. The age distribution of the herd over this period is given. There is no evidence of any changing effect of the observed sex and age distributions on either birth rate or dispersal rate within the range of the data available. Dispersal is not related to herd size or to the number of yearlings present in the herd and appears to be primarily a function of factors extrinsic to the herd itself.

\section{Acknowledgments}

This material constituted part of a thesis submitted in partial fulfillment of the requirements for the degree of Master of Arts at the University of British Columbia. I should like to express my thanks to Dr. I. McT. Cowan for his assistance in supervising this work, to Dr. P. A. Larkin for his many useful suggestions regarding the treatment of the data, and to $\mathrm{Mr}$. T. G. Douglas, supervisor of the Reindeer Station, for his help and suggestions while I was carrying out this work. This study was financed by a grant from the Northern Research Coordination Centre of the Federal Department of Northern Affairs and National Resources. I was supported during the term 1958-1959 by a Studentship from the National Research Council of Canada.

\section{References}

Andrewartha, H. G., and L. C. Birch. 1954. The distribution and abundance of animals. Chicago: Univ. of Chicago Press. 782 pp.

Chitty, D. 1955. Allgemeine Gedankengänge über die Dichteschwankungen bei der Erdmaus (Microtus agrestis). Z. Säugetierkunde 20:55-60.

Crerar, T. A., and R. H. G. Bonnycastle. 1936. Canada's reindeer experiment. Trans. N. A. Wildl. Conf. 1:424-7.

Errington, P. L. 1954. On the hazards of overemphasizing numerical fluctuations in studies of "cyclic" phenomena in muskrat populations. J. Wildl. Mgnt. 18:66-90.

Kelsall, J. P. 1957. Continued Barren-Ground caribou studies. Can. Wildl, Serv., Wildl. Mgnt. Bull., Ser. 1 , No. 12,148 pp.

Krebs, C. J. 1959. Growth studies in the reindeer (Rangifer tarandus) with an analysis of population changes in the Mackenzie Delta herd over the period 1938-1958. M. A. Thesis, Univ. of British Columbia. $164 \mathrm{pp}$., unpublished.

Kluijver, H. N. 1951. The population ecology of the great tit, Parus m. major L. Ardea 39:1-135.

Porsild, A. E. 1929. Reindeer grazing in northwest Canada. Ottawa: King's Printer, $46 \mathrm{pp}$.

Pulk, M. 1958. Personal communications.

Snedecor, G. W. 1956. Statistical methods. Ames: Iowa State College Press, 534 pp. Walker, H. M., and J. Lev. 1953. Statistical inference. New York: Holt and Co., 510 pp. 